\title{
Modification of polyacrylamide- $\beta$-zeolite composite by phytic acid for the removal of lead from aqueous solutions
}

\author{
Hossein Faghihian*, Sepideh Nazari Farsani \\ Department of Chemistry, Shahreza Branch, Islamic Azad University, P.O. Box 311-86145, Shahrza, Isfahan, Iran \\ * Corresponding author: Faghihian@iaush.ac.ir
}

\begin{abstract}
Polyacrylamide-zeolite composite was prepared by direct polymerization of polyacrylamide in suspensions of $\beta$-zeolite. Phytic acid was then immobilized on the composite surface. Fourier transform infrared spectrometry (FT-IR), X-Ray Diffraction (XRD) and Thermal gravimetry (TG) techniques were employed to characterize the synthesized adsorbent. The adsorptive features of the composite and the modified composite were investigated for the removal of $\mathrm{Pb}^{2+}$ from aqueous solution in view of dependency on $\mathrm{pH}$, time, ion concentration, temperature, selectivity, kinetics and reusability. The adsorption isotherms were evaluated with reference to the Langmuir and Freundlich models. Thermodynamic of the system was calculated. $\Delta \mathrm{G}<0$ indicated that the adsorption process was spontaneous. Good compatibility of the adsorption kinetics to the pseudo-second-order model predicted that the rate-controlling step was a chemical sorption. The selectivity experiments showed that the adsorbents were selective toward $\mathrm{Pb}^{2+}$ in the presence of $\mathrm{Zn}^{2+}$ and $\mathrm{Cd}^{2+}$. The reusability of the adsorbent was tested for four regeneration cycles.
\end{abstract}

Keywords: adsorption, lead, composite, polyacrylamide, phytic acid.

\section{INTRODUCTION}

Lead is potentially a very toxic cation. Its presence in the environment occurred as a result of extensive and wide applications of mining, chemical, electroplating, petroleum refining, paper and pulp industries ${ }^{\mathbf{1}, 2}$. Through the food chain system $\mathrm{Pb}^{2+}$ is transferred into animals and human beings, causing severe contamination ${ }^{3}$. For the protection and restoration of the environment adsorption of the contaminants by suitable adsorbents is considered as the most attractive method, because of its efficacy, practicality, and economical feasibility ${ }^{4,5}$. Among the different materials that have been used for the adsorption of the metal ions from solutions are clays and zeolites. Zeolites are infinitely tetrahedral network of aluminosilicates linked together by corner-sharing oxygen. The tedrahedra are arranged in interconnecting channels and apertures to form crystalline structure ${ }^{1,6}$. Beta zeolite is a high-silica zeolite possessing a three-di-mensional system of large rings (rings of 12 oxygen atoms as the minimum constricting apertures) ${ }^{7}$. Although the aluminosilicate based materials are desirable compounds for adsorption processes, aggregation and coagulation in aquatic environments are undesired features limiting their practical usage.

This limitation can be minimized by the use of mineral-polymer composites. Polymers have attracted great interest because they are easily and effectively produced in a wide variety of compositions, and exhibit specific sorption properties after modification with various functional groups ${ }^{8}$. Polyacrylamide (PAA) is a hydrogel, which being a crosslinked polymer consists of acrylamide monomers and N,N'-methylenebisacrylamid (crosslinking agent). PAA imbibes a considerable quantity of water, up to swelling equilibrium and can be practically used in adsorption investigations with appropriate structural modifications ${ }^{\mathbf{9}, 10}$. The adsorption properties of the composites made by aluminosilicates and PAA can be enhanced by further modification. The practical applicability of this approach has been reported for the composite of bentonite and zeolite with polyacrylamide for $\mathrm{Fe}^{3+}, \mathrm{Zn}^{2+}, \mathrm{UO}_{2}{ }^{2+}$ and $\mathrm{Pb}^{2+}$ adsorption. ${ }^{1,5}$ Phytic acid 1,2,3,4,5,6 hexakis (di-hydrogen phosphate) myo-inositol, is a very important molecule from a biological, environmental and technological point of view ${ }^{\mathbf{1 1}}$. Phytic acid, a hexaphosphate-substituted inositol ring compound is a renewable resource. It is the cyclic alcohol (cyclitol) derivative of glucose, water soluble and ubiquitous plant product readily available in large quantities. Phytic acid has 12 replaceable protons, of these 6 are strongly dissociable. Therefore, it exists as a negatively charged molecule over a wide $\mathrm{pH}$ range. With this feature, it has a high affinity to form phytate complexes with positively charged multivalent metal cations ${ }^{1}$. Phytic acid can be used to modify the surface properties of many adsorbents. The molecular structure of phytic acid is shown in (Fig. 1) ${ }^{\mathbf{1 1}}$.

The aim of this investigation was to modify polyacrylamide- $\beta$-zeolite composite with phytic acid

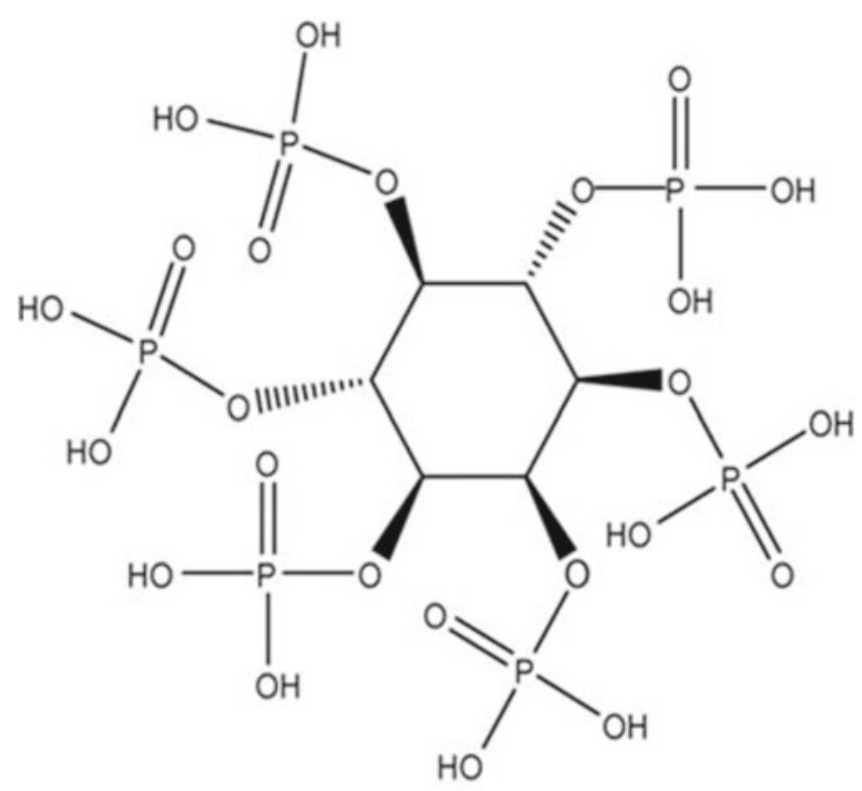

Figure 1. Basic structure of phytic acid 
(PAA-Z-Phy) and to study the modified composite for adsorption of $\mathrm{Pb}^{2+}$ from aqueous solution. The adsorptive features of the composite with reference to the dependency on $\mathrm{pH}$, concentration, temperature and time were also investigated.

\section{EXPERIMENTAL}

\section{Reagents and chemicals}

TEAOH (tetraethyl ammonium hydroxide) from Aldrich, $\mathrm{NaAlO}_{2}, \mathrm{KCl}, \mathrm{NaOH}$, aerosil-200 silica, N,N'-methylenebisacrylamid, N,N,N',N'-tetramethylethylenediamine and Na-phytate (Inositol hexaphosphoric acid in the form of dodecasodium salt; $\mathrm{C}_{6} \mathrm{H}_{6} \mathrm{O}_{24} \mathrm{P}_{6} \mathrm{Na}_{12}$ were purchased from Sigma (USA)); AA (Acrylamid monomer), $\mathrm{Pb}\left(\mathrm{NO}_{3}\right)_{2}, \mathrm{NaOH}$ and $\mathrm{HNO}_{3}$ were obtained from Merck(Germany). All chemicals used were of analytical reagent grade. Distilled water was used in all the investigations.

\section{Apparatus}

Zeolite, PAA-Z and PAA-Z-Phy samples were characterized by a series of complementary analytical techniques. Infrared Fourier transform spectroscopy was carried out using a (Nicolet 400D Impact spectrum single FT-IR machine) at wavenumbers $400-4000 \mathrm{~cm}^{-1}$ by using $\mathrm{KBr}$ pellets. The structural studies were performed by X-Ray diffractometry (Bruker, Diffractometer D8 ADVANCE, Germany) using $\mathrm{Cu} \mathrm{K \alpha}$ as radiation source and $\mathrm{Ni}$ as filter. The thermal curves were obtained using a SetarAm TG-DSC thermobalance (range $25-700^{\circ} \mathrm{C}$ ). The atmosphere was pure nitrogen and the heating rate of $10^{\circ} \mathrm{C} \min ^{-1}$ was used.

\section{Synthesis of Beta Zeolite}

A mixture containing $120.0 \mathrm{~g}$ of $20 \mathrm{wt} \% \mathrm{TEAOH}$ solution, $2.22 \mathrm{~g}$ of $\mathrm{NaAlO}_{2}, 0.90 \mathrm{~g}$ of $\mathrm{KCl}$, and $0.15 \mathrm{~g}$ of $\mathrm{NaOH}$ was stirred until it became a transparent solution. Then $32.59 \mathrm{~g}$ of aerosil-200 silica was added. The resulting homogeneous sol was transferred into a Teflon-lined stainless-steel autoclave and heated to $170^{\circ} \mathrm{C}$ statically. After $40 \mathrm{~h}$, the autoclave was quenched, the content filtered, and the solid was washed with deionized water. After drying at $96^{\circ} \mathrm{C}$ overnight, it was calcined at $540^{\circ} \mathrm{C}$ for $20 \mathrm{~h}$. The product was characterized by different characterization techniques ${ }^{12}$.

\section{Preparation of polyacrylamide-zeolite composite}

A mixture of $1.0 \mathrm{~g}$ of zeolite in $20 \mathrm{ml}$ of distilled water was stirred for 30 minutes to obtain a homogenously dispersed suspension. $2.0 \mathrm{~g}$ of acrylamide monomer, $0.20 \mathrm{~g}$ of N,N'-methylenebisacrylamid and $5.0 \mathrm{mg}$ ammoniumpersulphate were dissolved in $10 \mathrm{ml}$ of distilled water. The solution was then added to the zeolite suspension. The mixture was stirred for additional 10 minutes. $100 \mu \mathrm{l}$ of N,N,N',N'-tetramethylethylenediamine was then added to propagate the polymerization. After the completion of polymerization, the polyacrylamide-zeolite (PAA-Z) gel was washed with distilled water until the effluent attained neutral $\mathrm{pH}$. The final composition of the composite had a 2:1 mass ratio of PAA to zeolite. The gel was dried at ambient temperature, ground and sieved to particle size of $1 \mathrm{~mm}$, and stored in a container ${ }^{12}$.

\section{Modification of composite by phytic acid}

Solution of $4.5 \times 10^{-3} \mathrm{M}$ of phytate was prepared by dissolving the required amount of sodium phytate in distilled water. $10 \mathrm{ml}$ portions of the phytate solution were added to $0.1 \mathrm{~g}$ of PAA-Z in polypropylene bottles. The $\mathrm{pH}$ of the solutions was adjusted within the range of 9-11. The adsorbent-solution systems were then equilibrated for 24 hours by occasional shaking at $25^{\circ} \mathrm{C}$. The suspensions were centrifuged at $3000 \mathrm{rpm}$ for 10 minutes and the supernatants were separated. The solid (PAA-Z-Phy) in the form of gel was washed by distilled water until the water conductivity was attained. Phytate adsorption onto the PAA- $Z$ was confirmed by comparing the FT-IR spectra and thermal analysis curves of PAA-Z with PAA-Z-Phy ${ }^{1}$.

\section{Adsorption studies}

Batch adsorption experiments were conducted in 100 $\mathrm{ml}$ stoppered reagent bottles. A measured amount $(0.2 \mathrm{~g})$ of PAA-Z and PAA-Z-Phy composites were placed into the $100 \mathrm{ml}$ reagent bottles, which containing $25 \mathrm{ml}$ of various concentrations of $\mathrm{Pb}^{2+}$ solution. The solution $\mathrm{pH}$ was adjusted to the desired value by adding $\mathrm{HNO}_{3}$ or $\mathrm{NaOH}$ solution and the bottles were shaken at $200 \mathrm{rpm}$ at room temperature using a mechanical shaker for a prescribed length of time to attain equilibrium. The effect of the initial metal ion concentration (100-2500 ppm), contact time (30-1440 min) and solution $\mathrm{pH}(2.0-5.0)$ on the adsorption of $\mathrm{Pb}^{2+}$ was studied. After centrifugation at $3000 \mathrm{rpm}$ for $10 \mathrm{~min}$ the concentration of $\mathrm{Pb}^{2+}$ was measured by Atomic Absorption Spectroscopy method (Perkin Elmer A Analyst 300).

\section{Time dependence $\mathbf{P b}^{2+}$ adsorption}

To study the adsorption kinetic, $0.20 \mathrm{~g}$ of sample was equilibrated with $25 \mathrm{ml}$ of $\mathrm{Pb}^{2+}$ solution (400 ppm) and the $\mathrm{pH}$ of the solution was adjusted to $\mathrm{pH}=4$. The adsorbent-solution systems were then equilibrated by occasional shaking at $25^{\circ} \mathrm{C}$ for contacting time within the range of $0.5-24 \mathrm{~h}$. The suspensions were centrifuged and the $\mathrm{Pb}^{2+}$ concentration was measured.

\section{Concentration dependence of $\mathbf{P b}^{2+}$ adsorption}

The concentration dependence of adsorption was investigated for PAA-Z and PAA-Z-Phy samples. $0.20 \mathrm{~g}$ of sample was equilibrated with $25 \mathrm{ml}$ of $\mathrm{Pb}^{2+}$ solution within the range of $100-2500 \mathrm{mgL}^{-1}$ at $\mathrm{pH}=4$. The adsorbent-solution system was then equilibrated for 2 hours by occasional shaking at $25^{\circ} \mathrm{C}$. The suspension was centrifuged and the $\mathrm{Pb}^{2+}$ concentration was measured.

\section{Temperature dependence of $\mathrm{Pb}^{2+}$ adsorption}

For the determination of thermodynamic parameters the effect of temperature on adsorption was studied at four temperatures of $298,308,318$ and $328 \mathrm{~K} .0 .20 \mathrm{~g}$ fractions of the samples were equilibrated with $25 \mathrm{ml}$ solution $\left(1500 \mathrm{mgL}^{-1}\right)$ of $\mathrm{Pb}^{2+}$ at $\mathrm{pH}=4$ for $2 \mathrm{~h}$. After equilibration, the mixture was centrifuged and the $\mathrm{Pb}^{2+}$ concentration was measured in aqueous phase.

\section{Reusability of the adsorbent}

$0.20 \mathrm{~g}$ of the PAA-Z-Phy loaded with $\mathrm{Pb}$ in a column with a glass-wool cover was eluted with $25 \mathrm{ml}$ of 
$0.5 \mathrm{~mol} / \mathrm{L} \mathrm{HNO}_{3}$ with flow rate of $2 \mathrm{ml} \mathrm{min}{ }^{-1}$. The recovery of $\mathrm{Pb}^{2+}$ with $\mathrm{HNO}_{3}$ was determined. The column was then reconditioned with distilled water until the effluents had a neutral $\mathrm{pH}$. The regeneration step was repeated for four regeneration cycles ${ }^{8}$.

\section{RESULTS AND DISCUSSION}

\section{Characterization of the adsorbents}

The FT-IR spectra of $\beta$-zeolite, PAA-Z, Phytic acid and PAA-Z-Phy are given in (Fig. 2). The bands within the range $1000-1300 \mathrm{~cm}^{-1}$ and $400-700 \mathrm{~cm}^{-1}$ attributed to the zeolite structure (Fig. 2a). The peaks at $3200 \mathrm{~cm}^{-1}$ of $\mathrm{N}-\mathrm{H}$ and $1700 \mathrm{~cm}^{-1}$ of $\mathrm{C}=\mathrm{O}$ of amide are observed in the spectrum of PAA-Z (Fig. 2b). The peaks at 1322 $\mathrm{cm}^{-1}$ of $\mathrm{C}-\mathrm{O}, 1755 \mathrm{~cm}^{-1}$ of $\mathrm{P}=\mathrm{O}$ and $3527 \mathrm{~cm}^{-1} \mathrm{O}-\mathrm{H}$ of acid are observed in the spectrum of phytic acid (Fig. 2c).

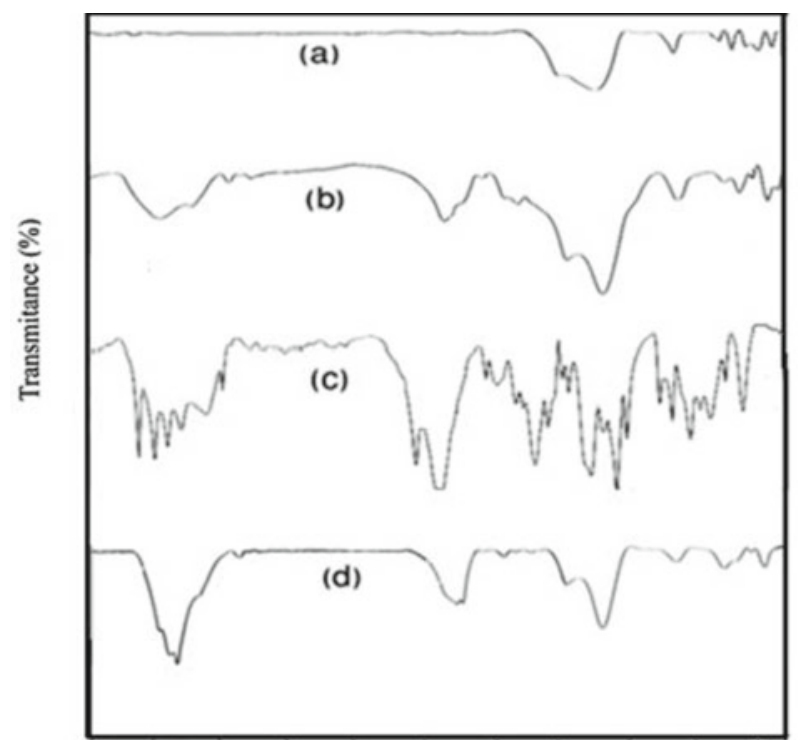

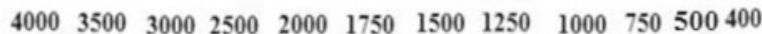

$$
\text { Wavenumber } / \mathrm{Cm}^{-1}
$$

Figure 2. FT-IR spectra of (a) Zeolite (b)PAA-Z (c)Phy (d) PAA-Z-Phy

Fig. 3 shows the XRD pattern of zeolite, PAA-Z and PAA-Z-Phy samples. No major shift in the position of the lines was observed showing that the structure of zeolite remained intact upon the treatments. It was concluded from the IR spectra and XRD patterns of zeolite and PAA-Z-Phy that the zeolite particles were uniformly dispersed in the polymer. The interfacial interaction between PAA and zeolite was achieved by binding the formation between PAA and the siloxane oxygen atoms or hydroxylated sites of zeolite ${ }^{\mathbf{1 , 9}}$.

The TG and DTG curves of zeolite, PAA-Z and PAA-Z-Phy are shown in (Fig. 4). The weight loss peak around $100^{\circ} \mathrm{C}$ is attributed to the loss of water and is observed in zeolite, PAA-Z and PAA-Z-Phy samples. Two extra weight loss peaks which are observed in the thermal curves of PAA-Z and PAA-Z-Phy are attributed to the decomposition of polyacrylamide and phytic acid.

\section{Effect of pH}

The effect of $\mathrm{pH}$ on the adsorption of $\mathrm{Pb}^{2+}$ by the adsorbents at initial lead concentration of $400 \mathrm{mg} \mathrm{L}^{-1}$,

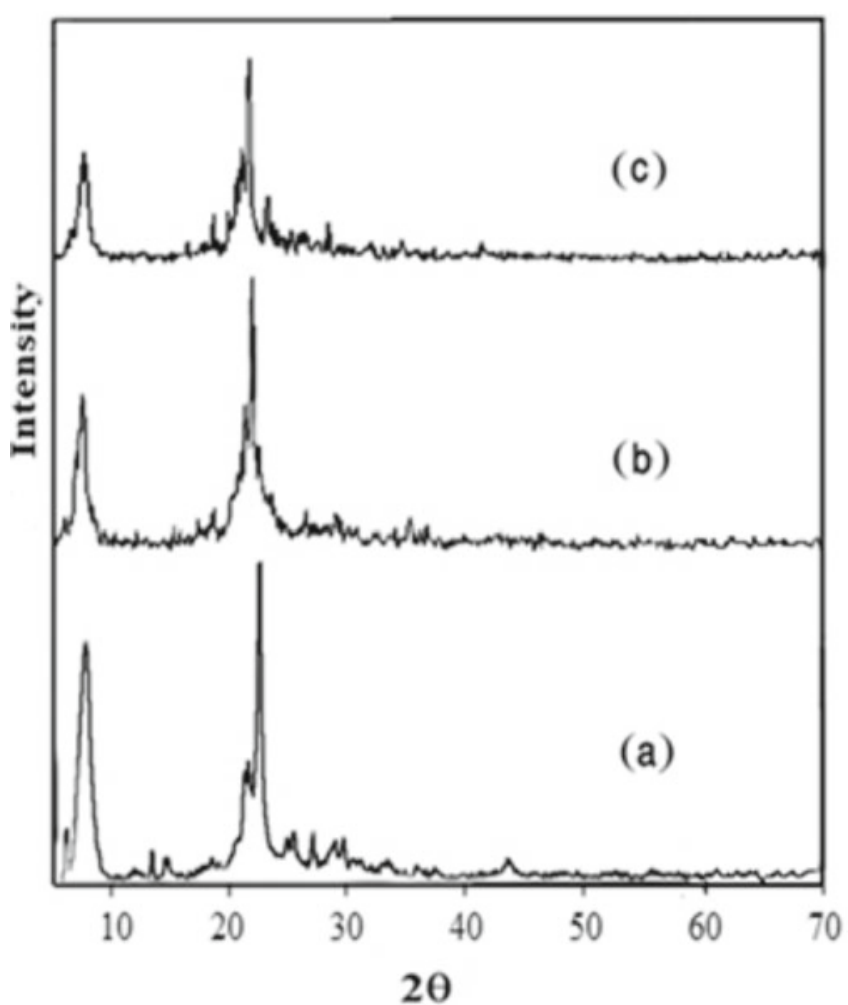

Figure 3. XRD spectra af (a)Zeolite- $\beta$ ) b)PAA-Z (c)PAA-Z-Phy

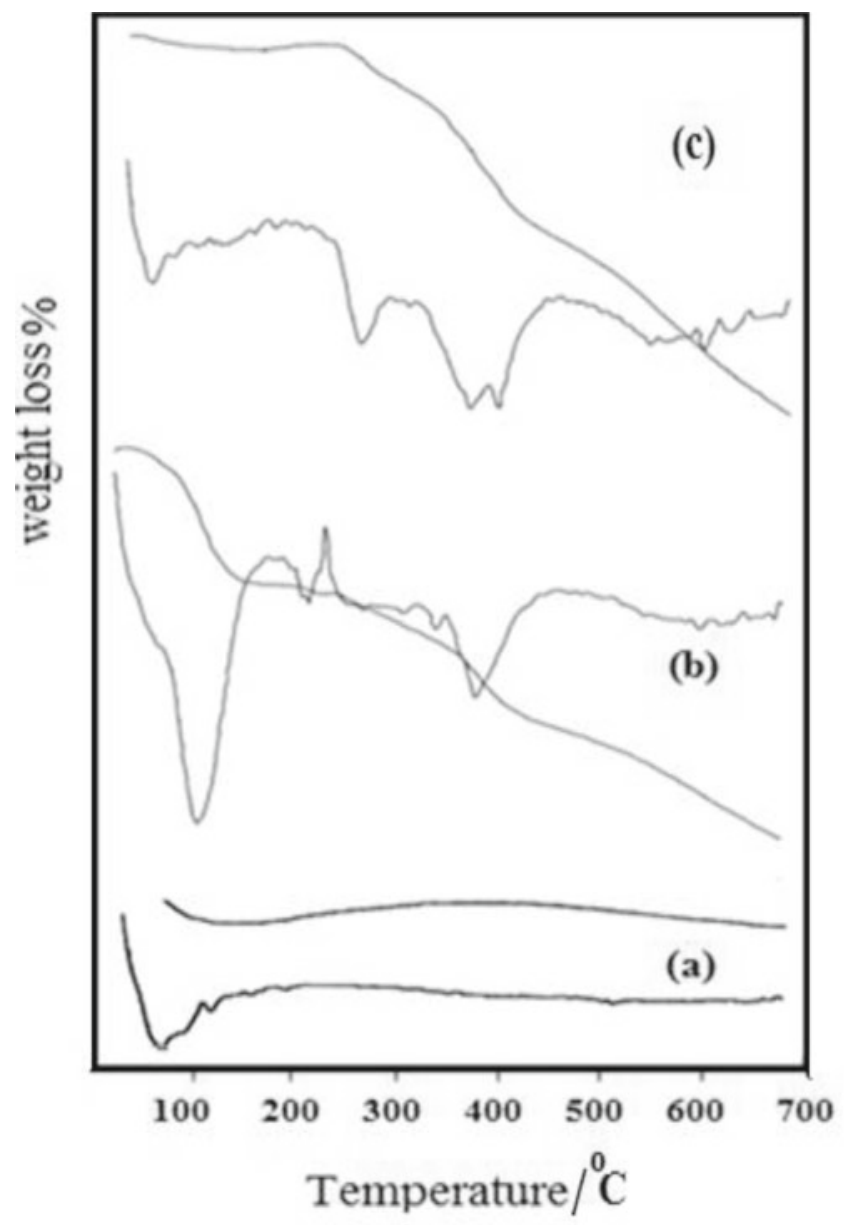

Figure 4. TG and DTG of (a)Zeolite (b)PAA-Z (c)PAA-Z-Phy

and samples dose of $0.2 \mathrm{~g}$ is shown in (Fig. 5). It is conceivable that at low $\mathrm{pH}$ values, where there is an excess of $\mathrm{H}_{3} 0^{+}$ions in the solution, a competition exists between the positively charged hydrogen ions and metal ions for the available adsorption sites on the adsorbents surface. 


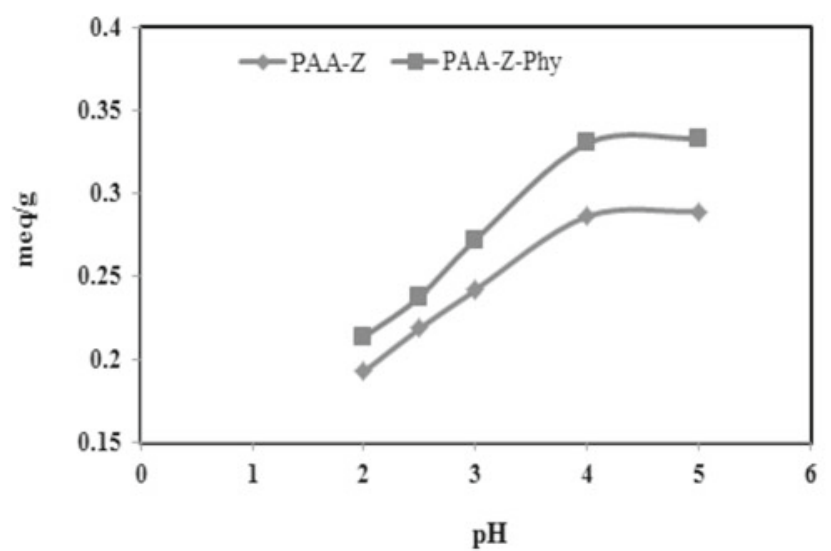

Figure 5. Dependence of $\mathrm{Pb}^{2+}$ adsorption on the $\mathrm{pH}$ of the solutions

As the $\mathrm{pH}$ increases and the balance between $\mathrm{H}_{3} 0^{+}$and $\mathrm{OH}^{-}$are more equal, more positively charged metal ions are adsorbed and the amount of adsorbed $\mathrm{Pb}^{2+}$ increased with increasing $\mathrm{pH}$ and reached a plateau around $\mathrm{pH}=4$. It is assumed that the surface of aluminosilicates had amphoteric $\mathrm{SiOH}$ sites in aquatic solutions and they were either protonated to form $\mathrm{SiOH}_{2}{ }^{+}$or deprotonated to form $\mathrm{SiO}^{-}$. $\mathrm{The}^{\mathrm{SiO}^{-}}$concentration increased with increasing $\mathrm{pH}$ whereas $\mathrm{SiOH}$ concentration decreased with increasing $\mathrm{pH}$ according to the following equation:

$\mathrm{SiOH}+\mathrm{H}^{+} \rightleftarrows \mathrm{SiOH}^{2+}$

$\mathrm{SiOH} \rightleftarrows \mathrm{SiO}^{-}+\mathrm{H}^{+}$

$2\left(\mathrm{SiO}^{-}\right)+\mathrm{Pb}^{2+} \rightleftarrows(\mathrm{SiO})_{2} \mathrm{~Pb}$

$2(\mathrm{SiOH})+\mathrm{Pb}^{2+} \rightleftarrows(\mathrm{SiO})_{2} \mathrm{~Pb}+2 \mathrm{H}^{+}$

\section{Adsorption isotherms}

Two adsorption isotherms, namely the Langmuir and the Freundlich were used to analyze the adsorption data. The Langmuir isotherm is based on monolayer adsorption on the active sites of the adsorbent. The Freundlich isotherm explains the adsorption on a heterogeneous surface with uniform energy. The Langmuir $\mathrm{q}=\left(\mathrm{K}_{\mathrm{L}} \mathrm{X}_{\mathrm{L}} \mathrm{C}_{\mathrm{e}}\right) /$ $\left(1+\mathrm{K}_{\mathrm{L}} \mathrm{Ce}\right)$ and Freundlich $\left(\mathrm{q}=\mathrm{X}_{\mathrm{F}} \mathrm{C}_{\mathrm{e}}^{1 / \beta}\right)$ models were fit to the isotherms experimentally obtained, where $X_{L}$ is the monolayer sorption capacity $\left(\mathrm{mg} \mathrm{g}^{-1}\right), \mathrm{K}_{\mathrm{L}}$ is the adsorption equilibrium constant $\left(\mathrm{L} \mathrm{mg}^{-1}\right)$ related to the Gibbs free energy change. $X_{F}$ and ' $1 / \beta$ ' are empirical Freundlich constants associated with the capacity and intensity of adsorption. These constants can be calculated from the slope and intercept of the linear plot, with log $\mathrm{q}_{\mathrm{e}}$ versus $\log \mathrm{C}_{\mathrm{e}}{ }^{13}$. The fitted constants for the Langmuir and Freundlich isotherm models along with regression coefficients $\left(\mathrm{R}^{2}\right)$ are summarized in (Table 1).

The experimentally attained adsorption isotherms and their compatibility to Langmuir and Freundlich models were provided in the values of the adsorption capacities $\left(\mathrm{X}_{\mathrm{L}}, \mathrm{X}_{\mathrm{F}}\right)$ for PAA-Z and PAA-Z-Phy for $\mathrm{Pb}^{2+}$. It is obvious that the introduction of phytic acid into PAA-Z remarkably improved its adsorption capacity (Table 1). This should be ascribed to the fine distribution of phytic acid in PAA-Z causing the increase in adsorptive surface and numbers of active sites available for adsorption.

\section{Thermodynamics of $\mathbf{P b}^{2+}$ adsorption}

The thermodynamic parameters such as change in free energy $(\Delta G)$, enthalpy $(\Delta H)$ and entropy $(\Delta S)$ were calculated from the following equations and listed in (Table 2). The distribution coefficients $\left(\mathrm{K}_{\mathrm{d}}\right)$ were derived from $K_{d}=\left[\left(C_{i}-C_{e} / C_{e}\right) V / W\right]$ for each temperature and $\ln K_{d}$ was depicted against $1 / T$ to provide adsorption enthalpy $\left(\Delta \mathrm{H}, \mathrm{J} \mathrm{mol}^{-1}\right)$ and entropy $\left(\Delta \mathrm{S}, \mathrm{J} \mathrm{mol}^{-1} \mathrm{~K}^{-1}\right)$ from the slopes $(\Delta \mathrm{H} / \mathrm{R})$ and intercepts $(\Delta \mathrm{S} / \mathrm{R})$ of the depictions with reference to $\operatorname{lnK}_{d}=(\Delta S / R-\Delta H / R T)$ shown in (Fig. 6). Where $\mathrm{R}$ is ideal gas constant, 8.314 $\left(\mathrm{J} \mathrm{mol}^{-1} \mathrm{~K}^{-1}\right)$ and $\mathrm{T}$ is the absolute temperature, $298^{\circ} \mathrm{K}$. The enthalpy changes were negative for the studied adsorbents, showing that the overall process was exothermic and the entropy change was positive for PAA-Z

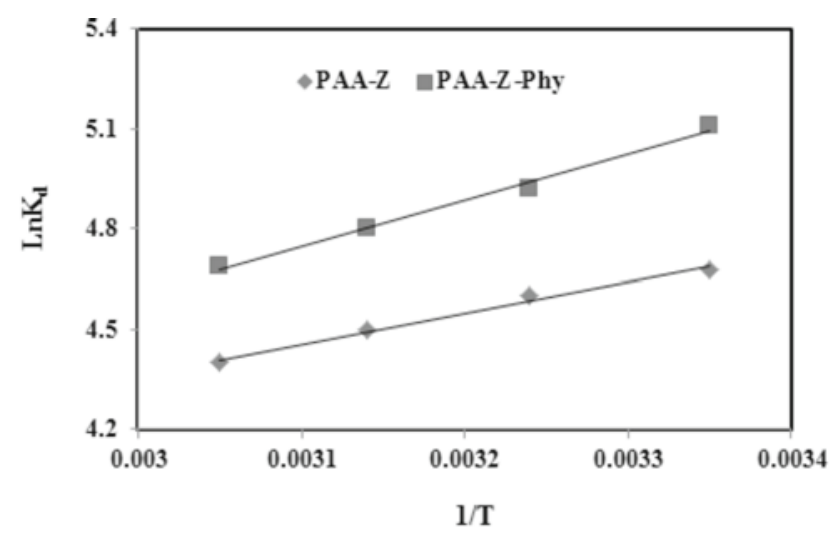

Figure 6. Temperature dependence of $\mathrm{Pb}$ adsorption onto PAA-Z and PAA-Z-Phy

and PAA-Z-Phy the positive values of $\Delta \mathrm{S}$ indicate that the randomness increased at the solid-solution interface during the adsorption of metals onto adsorbents. The gibbs free energy change was negative indicating that the adsorption process was spontaneous ${ }^{8}$.

\section{Kinetics of adsorption}

The kinetics of $\mathrm{Pb}^{2+}$ adsorption was tested with the pseudo-second order, pseudo-first-order and the intra-particle diffusion model. The pseudo-first-order kinetic model was given by Langergren and Svenska has been widely used to predict the adsorption kinetics by the equation, $\log \left(\mathrm{q}_{\mathrm{e}}-\mathrm{q}_{\mathrm{t}}\right)=\log \mathrm{q}_{\mathrm{e}}-\left(\mathrm{k}_{1} \mathrm{t}\right) / 2.303$. The plot of

Table 1. Langmuir and Freundlich parameters obtained for $\mathrm{Pb}^{2+}$ onto $\mathrm{PAA}-\mathrm{Z}$ and PAA-Z-Phy

\begin{tabular}{|l|c|c|c|c|c|c|}
\hline & \multicolumn{3}{|c|}{ Langmiur } & \multicolumn{3}{c|}{ Freundlich } \\
\hline & $\mathrm{X}_{\mathrm{L}} / \mathrm{mg} \mathrm{g}^{-1}$ & $\mathrm{~K}_{\mathrm{L}} / \mathrm{L} \mathrm{mg}^{-1}$ & $\mathrm{R}^{2}$ & $\mathrm{X}_{\mathrm{F}}$ & $\mathrm{R}^{2}$ & \multicolumn{2}{c|}{${ }^{2}$} \\
\hline PAA-Z & 116.3 & 0.0034 & 0.9322 & 6.96 & 2.13 & 0.897 \\
\hline PAA-Z-Phy & 142.8 & 0.0046 & 0.9474 & 7.80 & 2.66 & 0.949 \\
\hline
\end{tabular}

Table 2. Thermodynamic parameters for adsorption of $\mathrm{Pb}^{2+}$

\begin{tabular}{|l|c|c|c|c|}
\hline & $\Delta \mathrm{H} / \mathrm{kJ} \mathrm{mol}^{-1}$ & $\Delta \mathrm{S} / \mathrm{J} \mathrm{mol}^{-1} \mathrm{~K}^{-1}$ & $\Delta \mathrm{G} / \mathrm{kJ} \mathrm{mol}^{-1}$ & $\mathrm{R}^{2}$ \\
\hline PAA-Z & -7.78 & 12.92 & -11.63 & 0.9911 \\
\hline PAA-Z-Phy & -11.51 & 3.77 & -12.63 & 0.9911 \\
\hline
\end{tabular}


$\log \left(\mathrm{q}_{\mathrm{e}}-\mathrm{q}_{\mathrm{t}}\right)$ versus $\mathrm{t}$ gave the slope of $\mathrm{k}_{1}$ and the intercept $\log \mathrm{q}_{\mathrm{e}}$ (Fig. 7a). The amount of adsorption was calculated by $q=\left[\left(C_{i}-C_{e}\right) v / w\right]$, where $C_{i}$ and $C_{e}$ are the initial and equilibrium concentrations of the studied ion $\left(\mathrm{mg} \mathrm{L}^{-1}\right)$, $\mathrm{W}$ is the mass of adsorbent $(\mathrm{g})$ and $\mathrm{V}$ is the solution volume $(\mathrm{mL})$. The pseudo-second-order equation based on the equilibrium adsorption is expressed as $t / q_{t}=1$ / $k_{2} q^{2}+t / q$. The linear plot of $t / q_{t}$ versus $t$ can be used to determine $q_{e}$ and $k_{2}$ from slope and intercept of the plot (Fig. 7b) ${ }^{11}$. The pseudo-second-order model kinetics indicates that the rate-controlling mechanism is chemical process. ${ }^{14,15}$ The rate parameter of interparticle diffusion can be defined as $\mathrm{q}_{\mathrm{t}}=\mathrm{k}_{\mathrm{i}} \mathrm{d}_{\mathrm{t}}^{0.5}+\mathrm{C}$ where $\mathrm{q}_{\mathrm{t}}$ is the adsorbed amounts $\left(\mathrm{mg} \mathrm{g}^{-1}\right)$ at time $\mathrm{t}$ and equilibrium (Fig. $\left.7 \mathrm{c}\right) \mathrm{k}_{1}$, $\mathrm{k}_{2}$ and $\mathrm{k}_{\mathrm{i}}\left(\mathrm{mg} \mathrm{g}^{-1} \mathrm{~h}^{0.5}\right)$ are the rate constants were applied to kinetic studies in order to envisage the controlling mechanism of the adsorption process. If the regression of $\mathrm{q}_{\mathrm{t}}$ versus $\mathrm{t}^{0.5}$ is linear and passes through the origin, then interparticle diffusion is the sole rate-limiting step. The values of $\mathrm{k}_{\mathrm{i}}$ and $\mathrm{C}$ can be determined from the slope and intercept of the plots $q_{t}$ versus $t^{1 / 2}$. The regression was linear, but the plot did not pass through the origin, suggesting that adsorption involved intraparticle diffusion, but that was not the only rate-controlling step ${ }^{16-18}$.

The compatibility of the experimental data to the pseudo-first-order, pseudo-second-order kinetics and Weber-Morris intraparticle diffusion models were evaluated with reference to the statistical significance of linearity obtained from ' $\log \left(\mathrm{q}_{\mathrm{e}}-\mathrm{q}_{\mathrm{t}}\right)-\mathrm{t}$ ' ' $\mathrm{t} / \mathrm{q}_{\mathrm{t}}-\mathrm{t}$ ' and ' $\mathrm{q}_{\mathrm{t}}-\mathrm{t}^{0.5}$, plots. The results derived from the models were provided in (Table 3). The closeness to unity of coefficients of regression attained from the pseudo-second-order model and similarity of the values of adsorbed amounts at equilibrium obtained from the model $\left(\mathrm{q}_{\mathrm{e}}\right)$ and from the experiment (q) eventually confirmed that the nature of adsorption was concentration dependent.

\section{Selectivity of the adsorbents}

The selectivity of PAA-Z and PAA-Z-Phy sample for $\mathrm{Pb}^{2+}$ in the solutions containing combinations of ions at equivalent concentrations $\left(500 \mathrm{mg} \mathrm{L}^{-1}\right)$ was studied. $25 \mathrm{ml}$ fraction of solution containing the studied ions was contacted with $0.20 \mathrm{~g}$ of the adsorbents. After equilibrium $(24 \mathrm{~h})$, the concentration of the studied cations was measured in the filtrate. The reported tolerance limit is defined as the ion concentration causing a relative error $< \pm 5 \%$ (Table 4). Adsorbents showed the highest affinity for $\mathrm{Pb}^{2+}$ in the presence of $\mathrm{Zn}^{2+}$ and $\mathrm{Cd}^{2+}$. This can also be explained by the affects of the affective ionic charge and the parameters related to the affinity of $\mathrm{Pb}^{2+}$ to the adsorbents together with the ionic strength of the medium.

\section{Reusability}

The reusability feature of PAA-Z-Phy was tested for $\mathrm{Pb}^{2+}$ for four regeneration cycles (Table 5). The recovery percentage declined with the number of regenerations.

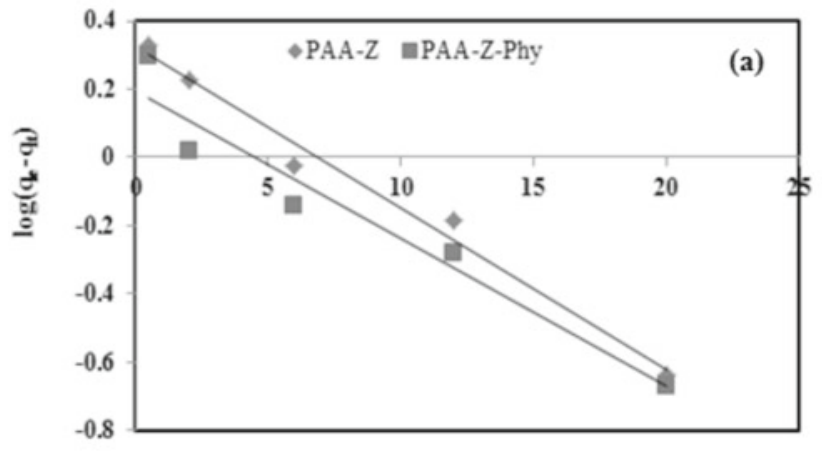

Time(h)
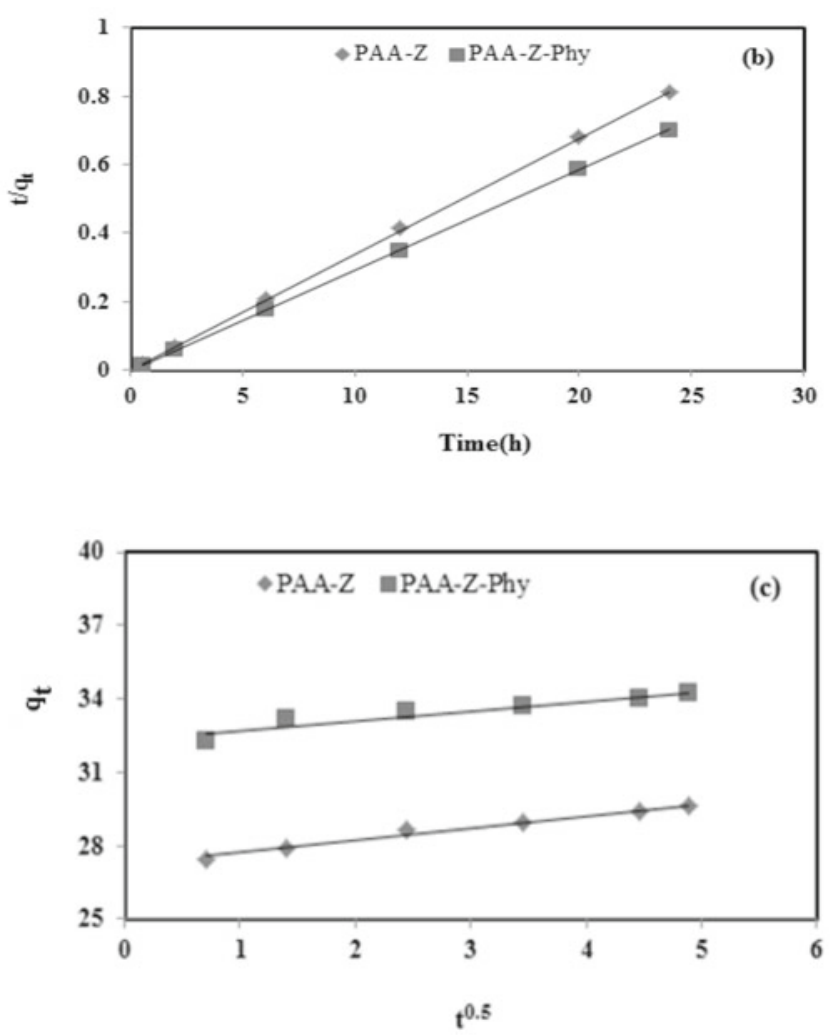

Figure 7. Compatibility of $\mathrm{Pb}$ adsorption kinetics for $\mathrm{PAA}-\mathrm{Z}$ and PAA-Z-Phy to (a)pseudo-one order $\log \left(\mathrm{q}_{\mathrm{e}}-\mathrm{q}_{\mathrm{t}}\right)$ vs.t (b)pseudo-second order ( $\mathrm{t} / \mathrm{q}_{\mathrm{t}}$ vs. $\mathrm{t}$ ) and (c)intraparticle diffusion $\left(\mathrm{q}_{\mathrm{t}}\right.$ vs. $\left.\mathrm{t}^{0.5}\right)$

This was attributed to blockage of adsorption centers or washing of some active sites during the regeneration procedure ${ }^{19}$. Regeneration is assumed to follow according to the equations:

$$
\begin{aligned}
& (\mathrm{SiO})_{2} \mathrm{~Pb}+2 \mathrm{H}^{+} \rightleftarrows 2(\mathrm{SiOH})+\mathrm{Pb}^{2+} \\
& \mathrm{SiOH}+\mathrm{H}^{+} \rightleftarrows \mathrm{SiOH}^{2+} \\
& \mathrm{SiOH}^{2+}+\mathrm{H}_{2} \mathrm{O} \rightleftarrows \mathrm{SiOH}+\mathrm{H}_{3} \mathrm{O}^{+}
\end{aligned}
$$

Table 4. Tolerance limit of PAA-Z, PAA-Z-Phy from solutions containing possible combination of studied ions at equivalent concentration (500ppm) of $\mathrm{Pb}^{2+}$

\begin{tabular}{|l|c|c|}
\hline & PAA-Z(ppm) & PAA-Z-Phy(ppm) \\
\hline $\mathrm{Cd}(\mathrm{II})$ & 2500 & 2500 \\
\hline $\mathrm{Zn}(\mathrm{II})$ & 2500 & 2500 \\
\hline
\end{tabular}

Table 3. Kinetic parameters for $\mathrm{Pb}^{2+}$ adsorption onto PAA-Z, PAA-Z-Phy

\begin{tabular}{|l|c|c|c|c|c|c|c|c|c|}
\hline & \multicolumn{3}{|c|}{ Pseudo first order } & \multicolumn{3}{c|}{ Pseudo second order } & \multicolumn{3}{c|}{ Intraparticle diffusion } \\
\hline & $\mathrm{K}_{1}$ & $\mathrm{q}$ & $\mathrm{R}^{2}$ & $\mathrm{~K}_{2}$ & $\mathrm{q}_{\mathrm{e}}$ & $\mathrm{q}$ & $\mathrm{R}^{2}$ & $\mathrm{~K}_{\mathrm{i}}$ & $\mathrm{R}_{2}$ \\
\hline PAA-Z & 0.109 & 2.11 & 0.9851 & 0.25 & 29.65 & 29.67 & 0.9999 & 0.49 & 0.9788 \\
\hline PAA-Z-Phy & 0.099 & 1.56 & 0.9404 & 0.57 & 34.22 & 34.24 & 1 & 0.39 & 0.8932 \\
\hline
\end{tabular}


Table 5. Reusability of PAA-Z-Phy for $\mathrm{Pb}$

\begin{tabular}{|l|c|}
\hline Recycle & \% regeneration \\
\hline 1 & 96.8 \\
\hline 2 & 94.8 \\
\hline 3 & 92.4 \\
\hline 4 & 90.5 \\
\hline
\end{tabular}

\section{CONCLUSION}

In this study, adsorptive features of PAA-Z and PAA-Z-Phy were investigated for $\mathrm{Pb}^{2+}$ adsorption. It was concluded that the amount of adsorbed $\mathrm{Pb}^{2+}$ was further increased by the modification of the composite PAA-Z with phytic acid. Thermodynamic studies showed that the adsorption process was endothermic and spontaneous. The experimental data were analyzed in terms of the Langmuir and Freundlich isotherm models and the data was well fitted by the Langmuir isotherm. Compatibility of adsorption kinetics to the pseudo second-order model indicated that the rate-controlling step is a chemical sorption. The kinetics of adsorption were fast, allowing its application in column operation. The adsorbent was regenerated for 4 cycles and showed that acceptable capacity remained after the last regeneration step.

\section{LITERATURE CITED}

1. Ulusoy, U. \& Şimşek, S. (2005). Lead removal by polyacrylamide-bentonite and zeolite composites: Effect of phytic acid immobilization. J. Hazard. Mater. 127, 163-171. DOI: 10.1016/j.jhazmat.2005.06.036.

2. Afridi, H.I. \& Kazi, T.G. \& Jamali, M.K. \& Kazi, G.H. \& Arain, M.B. \& Jalbani, N. \& shar, G.Q. (2006). Analysis of Heavy Metals in Scalp Hair Samples of Hypertensive Patients by Conventional and Microwave Digestion Methods. Spectrosc. Lett. 39, 203-214. DOI: 10.1080/00387010500531266.

3. Zhu, X. \& Cui, Y. \& Chang, X. Zou, X. \& Li, Z. (2009). Selective solid-phase extraction of lead(II) from biological and natural water samples using surface-grafted lead(II)- imprinted polymers. Microchim. Acta 164, 125-132. DOI: 10.1007/ s00604-008-0045-y.

4. Simsek, S. \& Ulusoy, U. \& Ceyhan, O. (2003). Adsorption of $\mathrm{UO}_{2}{ }^{2+}, \mathrm{Tl}^{+}, \mathrm{Pb}^{2+}, \mathrm{Ra}^{2+}$ and $\mathrm{Ac}^{3+}$ onto polyacrylamide-bentonite composite. J. Radioanal. Nucl. Chem. 256(2), 315-321. DOI: $10.1023 / \mathrm{A}: 1023953805247$.

5. Mistry, S.R. \& Joshi, R.S. \& Maheria, K.C. (2011). Zeolite H-BEA catalysed multicomponent reaction: One-pot synthesis of amidoalkyl naphthols - Biologically active drug-like molecules. J. Chem. Sci. 123(4), 427-432.

6. Cheetham, A.K. \& Nowak, A.K. \& Betteridge, P.W. (1986). Applications of molecular graphics to zeolite catalysts. J. Chem. Sci. 96(6), 411-418. DOI: 10.1007/BF02936295.

7. Xia, Q.H. \& Shen, S.C. \& Song, J. \& Kawi, S. \& Hidajat, K. (2003) Structure, morphology, and catalytic activity of $\beta$ zeolite synthesized in a fluoride medium for asymmetric hydrogenation. J. Catal. 219, 74-84. DOI: 10.1016/S0021-9517(03)00154-4.

8. Ulusoy, U. \& Akkaya, R. (2009). Adsorptive features of polyacrylamide-apatite composite for $\mathrm{Pb}^{2+}, \mathrm{UO}_{2}^{2+}$ and $\mathrm{Th}^{4+}$. J. Hazard. Mater. 163, 98-108. DOI: 10.1016/j.jhazmat.2008.06.064.

9. Ulusoy, U. \& Simsek, S. \& Ceyhan, O. (2003). Investigations for Modification of polyacrylamide-Bentoniteby Phytic Acid and its Usability in $\mathrm{Fe}^{3+}, \mathrm{Zn}^{2+}$ and $\mathrm{UO}_{2}{ }^{2+}$ Adsorption. Adsorption. 9, 165-175. DOI: 10.1023/A:1024297411400.

10. Anirudhan, T.S. \& Suchithra, P. (2009). Adsorption characteristics of humic acid-immobilized amine modified polyacrylamide/bentonite composite for cationic dyes in aqueous solutions S. J. Environ. Sci. 21, 884-891. DOI: 10.1016/ S1001-0742(08)62358-X.
11. Crea, F. \& De Stefano, C. \& Milea, D. \& Sammartano S. (2008). Formation and stability of phytate complexes in solution. Coord. Chem. Rev. 252, 1108-1120. DOI: 10.1016/j. ccr.2007.09.008.

12. Simsek, S. \& Ulusoy, U. (2004) UO22+, $\mathrm{Tl}+, \mathrm{Pb} 2+$, $\mathrm{Ra} 2+, \mathrm{Bi} 3+$ and Ac3+ adsorption onto polyacrylamide.zeolite composite and its modified composition by phytic acid. J. Radioanal. Nucl. Chem. 261(1), 79-86. DOI: 10.1023/B:JR NC.0000030938.98515.82.

13. Kalavathy, M.H. \& Karthikeyan, T. \& Rajgopal, S. \& Miranda, L.R. (2005). Kinetic and isotherm studies of $\mathrm{Cu}(\mathrm{II})$ adsorption onto H3PO4-activated rubber wood sawdust J. Colloid Interface Sci. 292, 354-362. DOI: 10.1016/j.jcis.2005.05.087.

14. Ulusoy, U. \& Akkaya, R. (2008). Adsorptive features of chitosan entrapped in polyacrylamide hydrogel for $\mathrm{Pb} 2+$, UO22+, and Th4+. J. Hazard. Mater. 151, 380-388. DOI: 10.1016/j.jhazmat.2007.05.084.

15. Kabbashi, N. \& Atieh, M. \& Al-Mamun, A. \& Mirghami, M. \& Alam, M. \& Yahya, N. (2009). Kinetic adsorption of application of carbon nanotubes for $\mathrm{Pb}(\mathrm{II})$ removal from aqueous solution. J. Environ. Sci. 21, 539-544. DOI: 10.1016/ s1001-0742(08)62305-0.

16. Hameed, B.H. \& Salman, J.M. \& Ahmad, A.L. (2009). Adsorption isotherm and kinetic modeling of 2,4-D pesticide on activated carbon derived from date stones. J. Hazard. Mater. 163, 121-126. DOI: 10.1016/j.jhazmat.2008.06.069.

17. El-Halwany, M.M. (2010). Study of adsorption isotherms and kinetic models for Methylene Blue adsorption on activated carbon developed from Egyptian rice hull (Part II). Desalination 250, 208-213. DOI: 10.1016/j.desal.2008.07.030.

18. Ahmaruzzaman, M. \& Laxmi Gayatri, S. (2010). Batch adsorption of 4-nitrophenol by acid activated jute stick char: Equilibrium, kinetic and thermodynamic studies. J. Chem. Eng. 158, 173-180. DOI: 10.1016/j.cej.2009.12.027.

19. Ulusoy, U. \& Senol, Z.M. (2010). Thallium adsorption onto polyacryamide-aluminosilicate composites: A Tl isotope tracer study. J. Chem. Eng. 162, 97-105. DOI: 10.1016/j. cej.2010.05.005. 